\title{
Advertisement Translation from the Perspective of Relevance Theory
}

\author{
Lei Yang \\ Wuhan Institute of Technology,No. 206, Optics Valley ,East Lake New Technology Development \\ Zone, Wuhan City, Hubei province,China,430205 \\ Email Address: 28446898@qq.com
}

Keywords: Advertising English, Relevance Theory, Advertising translation, Translating strategy

\begin{abstract}
Widespread advertisement has become an indispensable part of our daily life in this highly commercialized world. With the acceleration of economic globalization and increasingly open economic policy in China, more foreign companies come to China and more national enterprises step their feet in other countries. Under this circumstance, advertising translation has become an important part of translation. With the constant disputes among traditional translation criteria, the criterion of advertising translation has become very ambiguous and uncertain. Therefore, this thesis abandons the traditional translation theories such as "faithfulness, expressiveness, elegance”, “dynamic functional equivalence theory” and adopts Relevance Theory, an uprising pragmatic theory, to guide the advertising translation. It intends to reexamine the process of translation with the help of Relevance Theory and tentatively put forward feasible translating strategies to guide the translators.

Relevance Theory itself is not technically a translation theory. But due to the uniqueness of advertisement and the main task of advertising translation, it can be applied to guide the advertising translation. Although there is still some fuzziness and shortcomings in the practical application, the author believes Relevance Theory will have a stronger explanatory power and provide better guidance with the continuing perfection of the theory and the expansion of advertising translation practice.
\end{abstract}

\section{Introduction}

Advertising means different things to different people. It's a business, an art, an institution and a cultural phenomenon. Large amounts of money spent on ads nowadays. The market research firm Zenith Optimedia estimates that worldwide spending exceeds 400 billion US dollars per year. This level of spending supports thousands of companies and provides millions of Jobs. In fact, in many countries most media, such as television, radio and newspapers, are all supported by the advertisements and get a lot of profit from the ads.

Nowadays, more and more enterprises and companies set up their branches in china. Also many Chinese enterprises and companies promote sales overseas. When adopting the advertising strategy to promote sales, the advertiser should pay attention to the reaction of target audiences or readers. Thus, advertising translation plays an increasing significant role in modern advertising.

In this paper, the author abandons the traditional translation theories such as "faithfulness, expressiveness, elegance”, "dynamic functional equivalence theory” and adopts Relevance Theory, an uprising pragmatic theory, to guide the advertising translation. It intends to focus on the process of translation with the help of Relevance Theory and try to arise some feasible translating strategies to guide the advertising translators.

\section{Relevance Theory Approach to Ad Translation}

Relevance Theory itself is not technically a translation theory. But due to the uniqueness of advertisement and the main task of advertising translation, it can be applied to guide the advertising translation. Ernst-August Gutt, the scholar who has made pioneering study on the application of Relevance Theory to translation, pointed out that this theory "can help to better understand the nature of translation and some of the problems it typically involves." Also many Chinese translation 
theorists also approved that "Relevance Theory has the greatest explanatory power to translation which is the most complicated phenomenon in human history up to now" (Zhao Yanchun, 2003:1).

\section{Strategies on Advertisements Translation from Relevance Theory approach}

The translator's task is to bridge the gap between the advertiser and target receptors. Thus, he/she first should find the optimal relevance between the original advertiser's intention and the receptors' cognitive environment. Then he interpretate it and express the optimal relevance to the target audience. When he/she has done this work, the translator is free to use any kind of translation strategy and appropriate linguistic expression to fulfill his/her task.

Compared with literal translation, liberal translation is preferable in advertisement translation. Because when the translator adopt previous one, he /she has much freedom to bridge the gap between the advertiser and target audiences and also can do his/her best to convey the optimal relevance to the target audience.

In the following part of this thesis, the author analysis several ads translation strategies. All these strategies will change the original ads' form or source text's content when necessary. Moreover, the author use Relevance Theory to analysis the effects after adopting these translation strategies.

Addition. Addition means to add extra new information in the translation in order to suit the target language and culture, thus the rendering can achieve adequate pragmatic effects in the target environment and make the intention of the original advertiser manifest to the target audience. It is more than just explaining and supplementing the source text

Addition, the unique kind of translation strategy, is to add some more information in the target text. Even this new information doesn't exist in the source test. The purpose of adopting addition is that it can achieve adequate pragmatic effects in the target environment and help the target audiences know better about the original advertiser's intention. Because of the culture background, the source text may leave some obstacles to the target receptors. In ad translation, the translator infers the intention of the advertiser in the source text and the cognitive environment of the target audience, and ensures the rendering resembles the original text "closely enough in relevant respects" (Wilson and Sperber, 1988: 137, see Gutt, 1991). A competent ads translator should add some extra relevant information to obtain the optimal relevance. When applying addition in translation, the translator can "supply all the needed new information in a translation" (Gutt, 1991: 91) in order to achieve optimal relevance.

Abridgement. Abridgement in RT approach means to leave out It is slightly different from the traditional meaning of "abridgement", which indicates omitting the original sentences or information in a large scale to meet requirements of the target context.

Different from addition, abridgement is defined as a method to cancel the irrelevant information which may lead to the obstacles to the target audiences. In this following part the author exemplify how abridgement works in the ads translation in the light of Relevance Theory.

The main claim of Relevance Theory is to achieve optimal relevance with least effort. Thus the target receptors expect to get necessary information but no other extra information which will cost unnecessary effort. Thus the translator has "two related aims": first, "to create some contextual effect in the hearer", and second, "to minimize the processing effort this involves" (Gutt,1991: 202). Also the ads translation should "be clear and natural in expression in the sense that it should not be unnecessarily difficult to understand" (Gutt, 1991: 102). When adopting the strategy of abridgement in ads translation, the translator should omit the unnecessary and meaningless information given in the source text and try his best to make the target test more attractive and readable. Therefore, the target readers can use the least effort to achieve optima relevance.

Adaptation. Sometimes the form or content of the source text need to alter greatly to suit the local culture and cognitive environment of the target audience, in order to get good effects of the ads. This creative method is called adaption.

The standard of evaluation towards the rendition is the pragmatic effects it brings in the target context In the light of RT. Therefore, the target text has to achieve "likely effectiveness", "stimulate 
the thinking of the receptor language communicator" (Gutt, 1991: 65), and "manage to boost the sales" (Gutt, 1991:56). Because of the different language and culture background, people in these two nations have different thinking patterns. Thus, when using the method of adaption, the translator should first be acquaint with different preferences on language structures of target audiences in the two nations, then change the source text when necessary and recreate the image for the target audiences. Thus, the target audience can use least effort to appreciate the ads without any obstacle.

\section{Conclusion}

Having analyzed all the example of ads, the author has drawn a conclusion that relevance theory is an effective theory in the field of ads translation in some aspects. RT can be a guiding theory to ads translation though it is seldom used in this field.

Firstly, owing to the uniqueness and diversities of ads, the traditional translation theories can not always be the guide. It sometimes may fail to reach the expected effects. After the application of RT to translation, the situation has changed. Relevance theory emphasizes the contextual effects in the target environment. Because the aim of ads is to persuading the readers or the audiences to buy their products, or receive their services, or accept the advices, it represents well in the original text. Therefore the translator should help the readers or audiences to have a better understanding of the foreign products or services and consequently, help the foreign companies to promote their overseas sales. For these purposes, relevance theory may be more suitable to the ads translation.

Secondly, in ads translation, the role of the translator and his inference work is highly valued. In the guiding of RT, the translator has two inferential processes. First one is to seek out the relevance between the source text and its context, the other is to transfer it into the target text by inferring the cognitive environment and other factors of the target audience, and complete the interlingual communicative activity.

Lastly, the author has do some exemplifications and discussions in which Relevance Theory is applied to advertisement and advertising translation and several feasible translating strategies are demonstrated with illustrations. The author also listed some ads translation methods. All these translation methods help the translated ad optimally relevant to the target audience and achieve better practical effects and successfully serve the ultimate purpose of ads.

\section{References}

[1] Bass, B.M. Stogdill's Handbook of Leadership. New fork: Free Press,1981.

[2] Brown, Geoffrey. A Practical Guide for Translators.Great Britain: The Cromwell Press Ltd., 2004.

[3] Catford. A linguistic Theory of Translation [M]. Oxford University Press, 1965:20

[4] Cross, Mary. Advertising and Culture: Theoretical Perspectives. New York: Praeger Publisher, 1996

[5] Crystal, D\&D. Davy. Investigating English Style.London: Longman,1983.

[6] Dahl, Stephan. Communications and Culture Transformation - Cultural Diversity, Globalization and Cultural Convergence. http://www.stephweb.com,1998.

[7] Duan, Shuangshuang. Translation: A Cross-cultural Perspective. Beijing: Foreign Affairs College,2003.

[8] Dyer, G. Advertising as Communication. London: Methuen, 1982.

[9] Frawley, William. Translation: Literary, Linguistic, and Philosophical Perspective. London: Associated University Presses, Inc, 1984. 
[10]Fu, Mengyuan. Relevance Theory and Pragmatic Approach to Translation. Wuhan: Huazhong Normal University, 2001.

[11] Geis, Michael. The Language of Television Advertising .New York: Academic Press, 1982.

[12]Gentzler, Edwin. Contemporary Translation Theories.. Shanghai: Shanghai Foreign Language Education Press, 2006.

[13] Graham, F Joseph. Difference in Translation..London: Cornell University Press Ltd., 1985 